\title{
A Study on the Relationship and Influence Between Motivation and Satisfaction of Ecotourism Visitors Based on IOT
}

\author{
Tai- Gi An ${ }^{1} \&$ Lim-Soo Shin ${ }^{2}$ \\ ${ }^{1}$ Dept. of Hotel Tourism Management, Gwang-ju University, South Korea \\ ${ }^{2}$ Dept. of Fisheries Ocean Industry Tourism and Leisure, Chonnm National University, South Korea \\ Correspondence: Lim-Soo Shin, Dept. of Fisheries Ocean Industry Tourism and Leisure, Chonnm National \\ University, South Korea. E-mail: master@mtr.kr
}

Received: April 9, 2020

Accepted: May 9, 2020

Online Published: May 23, 2020

doi:10.5430/rwe.v11n2p159

URL: https://doi.org/10.5430/rwe.v11n2p159

\begin{abstract}
Background/Objectives: All modern activities have been developed to manage the system fused with IoT Internet of Things. Tourism industry is also developing into a fusion and complex. Currently, the Internet of things is the most active field of use, and the development plan of the Internet of things and ecotourism is being studied very little. ICT convergence industry in other fields is considered to be a field with high potential growth potential from remote systems. The purpose of this study is to empirically verify the relationship and influence between the motivation and satisfaction of eco-tourism tourists.

Methods/Statistical analysis: In order to achieve the purpose of this study, literature research and empirical research were conducted in parallel. First, the concept and characteristics of ecotourism were examined based on IoT base through theses, journals, and other related materials, and theoretical considerations such as motivation, satisfaction, revisit intention and recommendation intention of tourist destinations were conducted. The reliability test was conducted to identify internal consistency using SPSS program, and factor analysis was conducted to verify validity.
\end{abstract}

Findings: In order to investigate the relationship between the motivation and satisfaction of visitors to IOT ecotourism, this study was conducted to investigate the relationship between the motivation and satisfaction. First, based on the previous studies, the characteristics and mutual relations are conceptually redefined through theoretical review of ecotourism, tourism motivation, and tourism satisfaction. Second, the relationship between tourism characteristics, tourism motivation, tourism satisfaction, and revisit recommendation intention was empirically verified for tourists visiting IOT eco-tourism sites. Third, it is intended to provide useful Infor-mation for the development and management of ecological tourist destinations and the tourists who visit ecological tourist destinations in the future.

Improvements/Applications: Despite the importance of IOT ecotourism, systematic research is insufficient. The reason is that the application of ecotourism is different from case to case, so it is difficult and it is applicable to various fields, so various approaches are possible. This study was conducted to investigate the relationship between the tourist's motives and tourist satisfaction, targeting various ecotourism resources of the Jindo Mystery Sea Road Festival.

Keywords: ecotourism, motivation, satisfaction, conservation value, IOT base, tourism industry, fusion and complex, recommendation intention

\section{Introduction}

Ecotourism is the fastest growing sector in the tourism market since 2000. According to the reported data, the global tourism market is growing by about $4 \%$ annually, ecotourism is growing by about $10-30 \%$, and the overall tourism market share is growing by $5-10 \%$. More than 20 years after the word ecotourism was born, the United Nations is drawing global attention to setting 2002 as the year of ecotourism. Similarly, the WTO also forecasts that ecotourism is growing 20-30\% annually and will reach 25\% this year (2012) (Baker and Crompton, 2000; Beerli and Martin, 2004). In Korea, the public's interest in the environment is increasing rapidly, and the number of tourists visiting natural areas with excellent conservation value is increasing rapidly every year. All modern activities were developed to manage integrated systems with the Internet of Things. Tourism industry is also developing into 
convergence and hybridization (Crompton, 1979). The Internet of Things (IoT) is expanding the service market through convergence and combination with various industries and is being applied to medical care, home, automobile, industry, transportation, construction, agriculture, environment, entertainment, energy, safety, food, etc. Currently, the Internet of Things is the most active field of utilization, and the development of the Internet of Things and ecotourism is very insufficient. The IOT convergence industry in other fields is regarded as a field with high potential growth potential from remote systems. The rapid aging and the increase in income level are the result of the analysis that consumers' interest is concentrated on 'health' and IoT technology is rapidly growing, focusing on ecotourism (Coleman, 1988; Dann, 1981). Ecotourism is a trip to see the nature and culture of the region and contribute to the local economy by providing facilities and environmental education considering the environment so that travelers can understand, appreciate and enjoy the natural area without adversely affecting the ecosystem or local culture.

The conditions of ecotourism are the preservation and maintenance of species of biological resources, the prevention of irreversible damage to resources, the maintenance and utilization of natural life, and the life of nature protection spirit. It refers to tourism activities that provide economic benefits to local residents and have high educational value considering the environmental acceptance ability of the natural environment.

In addition, ecotourism aims to understand the natural environment and cultural resources of the target area and to experience convergence with nature through professional education and commentary (Fakeye and Crompton, 1991). It can be defined as tourism that minimizes the negative impact on the natural environment and local culture of tourist destinations, becomes a source of financing to maintain and develop nature-protected areas, and provides economic opportunities to preserve natural resources to local residents by creating economic benefits to local communities.

Ecotourism means tourism that encourages tourists to recognize the ecotourism environment based on nature and guarantees the sustainability of business operations leading to nature conservation activities (Howard and Sheth, 1989; Meric \& Hung, 1998). The main subject of business operation is local residents living in tourist attractions, and one of the ultimate goals of ecotourism is to create economic effects for the local community. In other words, ecotourism is a tourism that includes both hardware and software, which minimizes environmental destruction and provides opportunities for learning about nature (Maslow, 1970; Management Based).

\section{Materials and Methods}

The concept of tourism motivation tourists want to experience more than one attraction of tourist attractions. The result that pure travel does not occur by one motive in tourism literature is a long legend, and the motivation of tourists is complicated (Oliver, 1980; Pearce, 1980). In many studies, it has been proved that not only the motivation of tourists but also the motivation of festival visitors is due to the combination of aspiration factors and discharge factors. The concept of tourism satisfactions at is faction tends to be measured at a specific place at a particular time, so it seems static, but satisfaction is dynamic and influenced by various factors. Especially, if the product use or service experience occurs over time, the satisfaction may vary greatly depending on the use or experience stage that the customer focuses on. Satisfaction can be seen as a passive response to the service that the customer receives or receives without thinking over time (Parasuraman et al., 1988; Pizam et al., 1978). It is a kind of joy to surprise in a positive way. If you have to remove the negative side of satisfaction, customer satisfaction can be a solution to your worries. Finally, when you have a mixture of positive negative experiences with products or services, you can say ambivalence (Poon, 1993; Tse \& Wilton, 1988). The questionnaire is a means to evaluate how eco-tourists evaluate the tourism motivation and tourism satisfaction obtained through theoretical research and how they think after participating in tourism. This study used a post-evaluation method to evaluate the places where tourists visiting the sea road of Jindo mystery visit. The questionnaire was composed of four categories including the areas where the tourist visited. The first part was the items related to tourism motivation, and 16 items were set up including items related to IOT ecological nature, items related to recreation or rest, and items related to ecological experience (Wight Pamela, 1996). The second part is related to tourism satisfaction, and it consists of 17 items such as items related to convenience of use, items related to management and preservation, items related to commentary or experience, and items related to naturality. The third part was the items related to the evaluation of IOT tourist destinations, and the three items were recommended, revisited, and total satisfaction (Wall, 1994). The survey method was used to distribute and collect questionnaires after the surveyor obtained the consent of the respondents, and the self-reported questionnaire method, which is the way the respondents read and respond to the questionnaire, was used (Gofe and Tulu, 2019); (Gökçen, 2019). There were 500 questionnaires distributed, but 387 questionnaires were confirmed as valid samples except 35 insincere responses. The data were analyzed through coding process and frequency analysis, 
reliability and validity verification, and regression analysis were used according to the purpose of use using SPSS statistical package.

\section{Results and Discussion}

The research model of this study was to show the relationship between the visiting motivation and the satisfaction of tourists who visited various ecotourism resources of Jindo Shinbi's Sea Road Festival. First, as shown in Figure 1, the motive of visiting eco-tourism will affect the satisfaction of tourists in IOT eco-tourism destination. Third, it will affect the motive of visit, tourism satisfaction and tourist satisfaction [Figure 1].

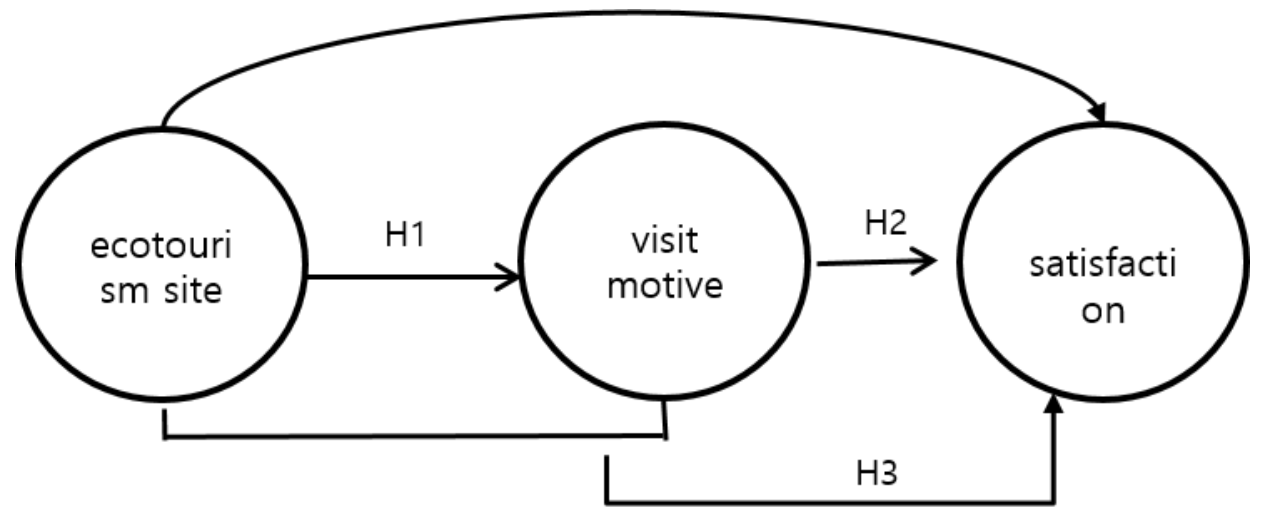

Figure 1. Research model

Described as shown in Rable 1. The characteristics of the subjects according to gender, age, education and education were $49.4 \%$ male and $50.6 \%$ female. $19.9 \%$ of women under $20,24.8 \%$ in their $30 \mathrm{~s}, 23.8 \%$ in their $40 \mathrm{~s}$, and $31.5 \%$ in their $50 \mathrm{~s}$ or older. The education level is $32.8 \%$ for high school graduates and $52.7 \%$ for college graduates. Income is $25.1 \%$ for $100 \sim 3$ million won and $49.4 \%$ for 3 million $\sim 5$ million won.

Table 1. Character analysis of research subjects

\begin{tabular}{llcc}
\hline & variable & $\begin{array}{c}\text { Frequency } \\
\text { (name) }\end{array}$ & percentage(\%) \\
\hline \multirow{3}{*}{ gender } & Female & 191 & 49.4 \\
& Male & 196 & 50.6 \\
\hline \multirow{5}{*}{ age } & 20 years & & \\
& 30 years & 77 & 19.9 \\
& 40 years & 96 & 24.8 \\
& over 50 years & 92 & 23.8 \\
Education & junior high school graduation & 122 & 31.5 \\
& high school graduation & 18 & 4.7 \\
& college graduation & 127 & 32.8 \\
& graduate school graduation & 204 & 52.7 \\
& & 38 & 9.8 \\
\hline \multirow{4}{*}{ importation } & & 15.0 \\
& one million won & 58 & 25.1 \\
& 100 to 3 million won & 97 & 49.4 \\
& 300 to 5 million won & 191 & 10.6 \\
& over five million won & 41 & \\
& & &
\end{tabular}


As shown in Table 2, the analysis results of the use propensity of the subjects were investigated. $47.8 \%$ of visitors to the tourist destination accompanied by family and relatives, $28.2 \%$ visited with friends, and $20.9 \%$ visited groups. $29.5 \%$ of the Internet and $27.9 \%$ of the friends recommended getting tourism information. $75.2 \%$ of the respondents were the first to visit, and $21.4 \%$ of the visitors were in the second to fifth visits. In the question related to transportation, $77.0 \%$ of visitors use their own cars.

Table 2. Use propensity analysis

\begin{tabular}{llll}
\hline & variable & frequency (name) & percentage(\%) \\
\hline \multirow{4}{*}{ Companion } & alone & 10 & 2.6 \\
& family \& relatives & 185 & 47.8 \\
& friend & 109 & 28.2 \\
& group & 81 & 20.9 \\
& guitar & 2 & .5 \\
\hline \multirow{3}{*}{ Tourism } & Broadcasting, Newspapers, & 38 & 9.8 \\
information & internet & 114 & 29.5 \\
& friend recommendation & 108 & 27.9 \\
& experience & 56 & 14.5 \\
Number of visits & guitar & 71 & 18.3 \\
& beginning & 292 & 75.5 \\
& 2-5 & 83 & 21.4 \\
& 6-9 & 6 & 1.6 \\
Traffic & more than 10 times & 6 & 1.6 \\
& car use & 298 & 77.0 \\
& public transportation & 18 & 4.7 \\
& group bus & 67 & 17.3 \\
& guitar & 4 & 1.0 \\
\hline
\end{tabular}

The result of analyzing the relationship with the overall satisfaction, which is the evaluation of tourist destinations for the motive of visit, is as shown in Table 3. The R-square value was 0.198 , and the three causes explained $19.8 \%$ of the total variance. In the case of the beach road festival of Jindo Mystery, which is the subject of the survey, the most influential factor on the overall satisfaction of visitors is nature experience.

Table 3. The Relationship between visiting motivation and total satisfaction

\begin{tabular}{lllll}
\hline Independent variable & $\begin{array}{l}\text { Dependent } \\
\text { variable }\end{array}$ & SF & $\mathbf{t}$ & p-value \\
\hline (Constant) & .996 & .257 & 3.879 & .000 \\
nature experience & .463 & .085 & 5.428 & .000 \\
learning ability & .151 & .087 & 1.731 & .084 \\
a landmark & .067 & .070 & .947 & .344 \\
\hline
\end{tabular}

R-square $=0.198$ 
The result of analyzing the relationship between the overall satisfaction, which is the evaluation of tourist destinations, on the factors of tourism satisfaction The same shall apply to Table 4 . R-square value is 0.409 , and 3 cause variables are $40.9 \%$ of total variance. In the case of the beach road festival of Jindo Mystery, which is the subject of the survey, it is the management of tourist attractions and the preservation of naturality that have a great influence on the tourism satisfaction factors and the overall satisfaction. As mentioned above, the results of analyzing the relationship between tourism motivation and tourism satisfaction for visitors to Jindo Shinbi's Sea Road Festival can be summarized and discussed in several categories as follows (George and Georgios, 2017); (Georgios and Maria-Rafailia, 2019). First, the subjects were distributed evenly according to gender and age, and the education level was found to occupy a high percentage of high school graduates and college graduates, so there was no significant difference from other tourist destinations in terms of demographics. As a result of analyzing the use tendency of the subjects, they often joined friends, family, friends, and relatives, and related information was also high in the rate of recommendation of internet and friends, and most of them visited for the first time and used tea. Second, in all items of tourism motivation and tourism satisfaction, respondents showed positive responses and it is judged that the level of trust and validity of the research data are secured. Therefore, there is no major contradiction in the design and survey method of the questionnaire using the research of the preceding researchers, and based on the results, it is judged that it can obtain similar implications to the evaluation of tourists visiting general ecotourism sites. Factors related to tourism motivation included tourism management, nature conservation, transportation, and information as natural experiences, learning, and reputation related to tourism satisfaction. Therefore, securing natural experience that can motivate tourists and delivering it to tourists is one of the important tasks of ecotourism. Third, the analysis of the impact of the factors of the tourism site evaluation on the motivation of the visit showed that it is related to the evaluation of the tourist site. In particular, it is expected to attract tourists with factors such as nature experience, learning, and reputation, which are tourism motivation factors, and reflect changes in tourist destination tendencies based on them.

\section{Conclusion}

Alternative tourism has begun to be sought to overcome the limitations and problems of popular tourism in the tourism sector. Ecotourism is one of the most popular areas of alternative tourism. Ecotourism is the fastest growing tourism with the aim of preserving the natural environment, benefiting local residents and educating tourists. Despite the importance of ecotourism, systematic research is insufficient. The reason is that the application of ecotourism is different from case to case, so it is difficult and it is applicable to various fields, so various approaches are possible. This study was conducted to investigate the relationship between the tourist's motives and tourist satisfaction, targeting various ecotourism resources of the Jindo Mystery Sea Road Festival. Recently, a tourist system that combines IOT-based tourist attractions and state-of-the-art technology will be a popular destination for visitors.

\section{Acknowledgment}

This Study was conducted by research funds from Gwangju University in 2020.

\section{References}

Baker, D. A., \& Crompton, J. L. (2000). Quality, satisfaction and behavioral intentions. Annals of Tourism Research, 27(3), 785-804. https://doi.org/10.1016/S0160-7383(99)00108-5

Beerli, A., \& Martin, J. D. (2004). Factors influencing destination image. Annals of Tourism Research, 31(3), 657-681. https://doi.org/10.1016/j. annals.2004.01.010

Coleman, J. S. (1988). Social capital in the creation of human capital. American Journal of Sociology, 94, 95-120.

Crompton, J. L. (1979). Motivations for pleasure vacation. Annals of Tourism Research, 6(4), 408-424.

Dann, G. (1981). Tourist motivation on appraisal. Annals of Tourism Research, 8(2), 187-219.

Fakeye, P. C., \& Crompton, J. I. (1991). Image differences between prospective: First time and repeat visitors to the Iower Rio Grande valley. Journal of Travel Research, 30(2), 10-16. https://doi.org/10.1177/004728759103000202

George, M., \& Georgios, M. M. (2017). The expansion of the contemporary economic role of crete throughout its extensive history. International Journal of Economics, Business and Management Studies, 4(1), 17-37.

Georgios, K., \& Maria-Rafailia, L. (2019). How mergers and acquisitions affected the basic accounting elements of Greek banks during the Euro years 2002-2018. Journal of Accounting, Business and Finance Research, 7(2), 24-39. https://doi.org/10.20448/2002.72.24.39 
Gofe, T. E., \& Tulu, D. R. (2019). Determinants of customers e-payment utilization in commercial bank of Ethiopia the case of Nekemte Town. Journal of Asian Business Strategy, 9(2), 120-132.

Gökçen, A. (2019). Explaining stress and depression level of nurses: The effects of role conflict and role ambiguity. International Journal of Management, 8(2), 61-66.

Howard, J. A., \& Sheth, J. N. (1989). The theory of behavior. John willed \& Sons. Retrieved from http://www.jstor.org/

Maslow, A. H. (1970). Motivation and personality (2nd ed.). New York: Harper \& Row.

Meric, H., \& Hung, J. (1998). Ecotourists motivational and demographic characteristics: A Case of North Carolina travelers. Journal of Travel Research, 36(4), 57-61.

Oliver, R. L. (1980, September). A cognitive model of the anticedents and consequences of satisfaction decisions. Journal of Marketing Research, 17, 46-49.

Parasuraman, A., Zeithaml, V. A., \& Berry, L. (1988, April). Communication and control processes in the delivery of service quality. Journal of Marketing, 52, 35-48. https://doi.org/10.2307/1251263

Pearce, E. (1980). Tourism's human conflicts: Toward more psychological approach. Annals of Tourism Research, 7(1), 122-136. https://doi.org/10.1111/j.1470-6431.2007.00606.x

Pizam, A., Neumann, Y., \& Reichel, A. (1978). Dimensions of tourist satisfaction with a destination area. Annals of Tourism Research, 5(3), 314-322. https://doi.org/10.1016/0160-7383(78)90115-9

Poon, A. (1993). Tourism technology and competitive strategy. CAB International Walling Ford.

Sharpley, R. (2002). Rural tourism and the challenge of tourism diversification: the case of Cyprus. Tourism Management, 23(3), 233-244.

Stone, L., James, C., Heung, C. O., Uysal, M., \& Weaver, P. A. (1995). Product Bundles and Market Segments Based on Travel Motivations: A canonical Corelation approach. International Journal of Hospitality Management, 14(2), 123-137.

Tse, D. K., \& Wilton, P. C. (1988). Models of consumer satisfaction formation: An extension. Journal of Marketing Research, 25(2), 204-212.

Wall, G. (1994). Ecotourism: Old wine in new bottles?. Trends, 31(2).

Wight Pamela, A. (1996). North American ecotourists marke profile and trip characteristics. Journal of Travel Research, 34(4), 1-19. 